University of St Andrews
STACEES

St Andrews Network for Climate, Energy, Environment and Sustainability

\title{
The Sustainability Series
}

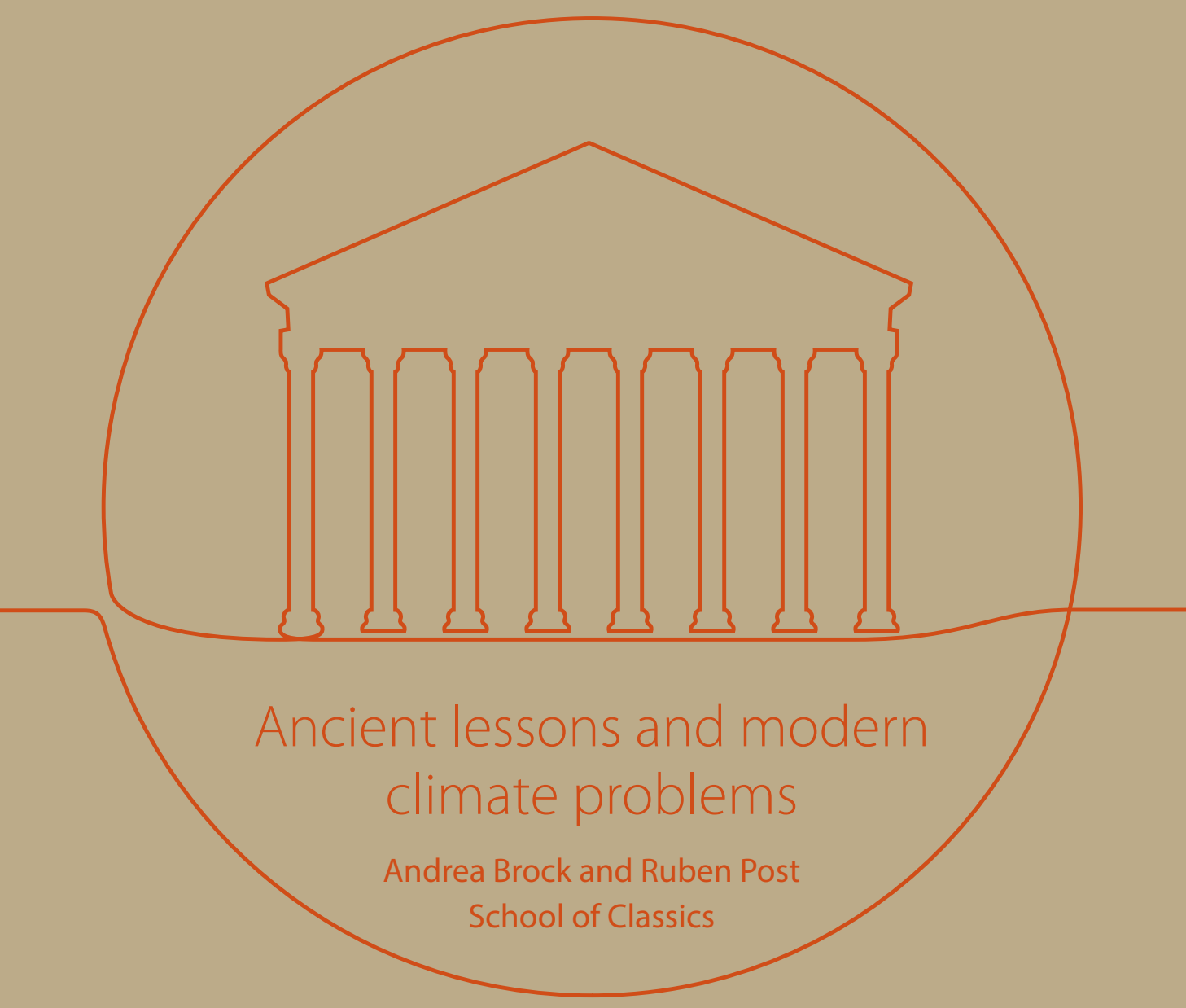




\title{
Ancient lessons and modern climate problems
}

\author{
Andrea Brock and Ruben Post - School of Classics \\ (Article written by Garry MacKenzie) \\ Copyright $\odot$ University of St Andrews 2021. For full terms, see end of article.
}

What can the ancient Greeks and Romans tell us about climate change? Is there anything we can learn from these societies as we address environmental challenges in our own time? Ancient Greece and Rome faced their own environmental problems. How did the inhabitants of those societies survive, and even thrive? How can their examples contribute to a greater understanding of climate change and sustainability among 21 st-century students of ancient history?

Thinking about the climate means thinking about long periods of time. This often involves considering the long-term environmental impacts of contemporary activities, such as burning fossil fuels and depositing plastics in landfills. At the same time, we risk getting stuck in a perpetually anxious present where we worry about our every action even as we are overwhelmed by the enormity of climate changes beyond the power of any individual to alter.

Dr Ruben Post and Dr Andrea Brock, researchers in the School of Classics, are working to draw attention to how people in ancient Greece and Rome managed changes in their environments. Their research encourages us to learn from the steps taken by ancient societies in response to environmental problems. As a result, we may consider how our own actions - from fuel consumption to recycling to holding politicians to account - can make a difference.

\section{Climate change and flooding in the ancient world}

Along with Professor Jason König, Post and Brock are co-directors of the Centre for Ancient Environmental Studies (CAES). Based in the School of Classics, CAES is an international network of scholars of literature, history, archaeology and the sciences working to uncover more about the environment of the ancient Mediterranean.

Funded by a Leventis Foundation Postdoctoral Fellowship, Post's research is an innovative combination of scientific, archaeological and historical evidence. Using scientific data, he reconstructs models for how the Greek climate changed during the first millennium BCE. He then adds crucial Greek crops into the equation: how were wheat, barley, grapes and olives affected by the climate? After establishing this climactic and agricultural framework, Post explores how the ancient Greeks felt about climate variability, the impact of extreme weather on their food supplies, and the communities most affected. What effect did climate fluctuations have on the economy and what measures did Greek communities take to ensure their survival? 
Previous studies have sought to understand the relationship between environmental problems and the collapse of pre-modern civilisations. But less attention has been given to the ancient societies that showed resilience in the face of environmental pressures. Post's research will contribute examples and lessons from the past that may help us better understand how to manage our own crisis in the present.

One of the main environmental challenges faced by the ancient inhabitants of Rome was flooding. Funded by a Leverhulme Early Career Fellowship, Brock's research involves analysing a new and unprecedented set of data from early Rome: geoarchaeological samples from over 15 metres below the modern-day surface of the city. Brock directs the Forum Boarium Project, a coring survey of Rome's central river valley that involves international and multidisciplinary collaboration between scholars working to reveal what the pre-urban landscape of Rome was like.

As the city grew in the first millennium $B C E$, the Tiber River valley changed dramatically. Floods became more destructive and sedimentation made it necessary for Romans to adapt, changing how they built, planned and lived on a floodplain. Because Rome provides one of the world's longest records of urban flooding, it offers an invaluable example for planners, governments and environmentalists facing rapidly expanding cities, rising sea levels and catastrophic flash floods in the 21st century.

\section{Interdisciplinarity, education, and learning from the past}

CAES is the first scholarly organisation specifically dedicated to ancient environmental studies. The projects led by Post and Brock are examples of the inherently interdisciplinary nature of the research that CAES brings together. Studying the ancient world means bringing together a variety of sources ranging from literary texts to soil samples, and from pottery to human remains.

Alongside their CAES research, Post and Brock are also pioneering a new environmental history curriculum for Scottish secondary school students. Building on their research into ancient Greek and Roman responses to environmental change, the curriculum will enable students to discover more about how environmental problems affect societies and how human activities have dramatically altered landscapes in turn. Shining a light on how past societies responded to ecological problems and developed resilience over time, the environmental history curriculum will offer a valuable and unique perspective for addressing modern ecological challenges.

One reason why Post and Brock are committed to developing a new school curriculum focused on the ancient environment is the multi-disciplinary approach of their own research. What better way to teach young people about complex issues, such as climate change, which require interdisciplinary and 
problem-solving approaches, combining scientific data with cultural study? With funding from the Royal Society of Edinburgh and the St Andrews Knowledge Exchange and Impact Fund, the materials for this new curriculum will be piloted in the 2021-2022 academic year.

Ultimately, they hope the curriculum will enable future generations to learn about why past societies either collapsed or proved resilient in the face of their own environmental crises. As the history of the ancient Mediterranean shows, the environment is ever changing. It has always impacted human society even as it has been impacted by human interventions. Studying the ancient environment encourages students to consider their own contemporary role: rather than seeing themselves as passive subjects of environmental change, students will be better equipped to evaluate how they can contribute to discussions about the environment at political, cultural and social levels.

Post and Brock view St Andrews, with its commitment to sustainability and interdisciplinary study, as the perfect home for their research. Through support from the St Andrews Network for Climate, Energy, Environment and Sustainability (STACEES), their work brings together a community of likeminded scholars exploring how their expertise can contribute to addressing the pressing environmental challenges of today.

\section{Find out more}

Centre for Ancient Environmental Studies (CAES) website: https://caes.wp.st-andrews.ac.uk/

Dr Andrea Brock researcher profile: www.st-andrews.ac.uk/classics/people/ abh1

Dr Ruben Post researcher profile: www.st-andrews.ac.uk/classics/people/ $\underline{\mathrm{rmp} 26}$ 
Publisher: St Andrews Network for Climate, Energy, Environment and Sustainability, University of St Andrews.

\section{Editors: Sarah Bennison and Laura Pels Ferra.}

Copyright: @ University of St Andrews 2021. All rights reserved. Licences issued by the Copyright Licensing Agency Limited do not extend to this work. The reproduction or transmission of all or part of the article, whether by photocopying or storing in any medium by electronic means or otherwise, without the written permission of the owner, is prohibited. The commission of any unauthorised act in relation to the work may result in civil or criminal actions.

Disclaimer: This article is one of a series of articles collectively entitled 'The Sustainability Series', written for STACEES, the St Andrews Network for Climate, Energy, Environment and Sustainability. STACEES is a research network at the University of St Andrews. The articles contained in the Series are based on research and may also contain opinion-based information. The opinions stated herein do not necessarily reflect the ideas, ideologies, or points of view of the Editors, the University of St Andrews or any other organisation.

\section{Neither the University of St Andrews nor the Editors or Author(s):}

- makes any warranties about the completeness, reliability and accuracy of the information contained herein and in particular takes no responsibility for the accuracy or otherwise of any part of the information contained herein (including any claims made herein) or for any errors or missing information. Any reader who relies on the information or views expressed in the article does so at their own risk. Any action taken as a result of the information or views contained in the article is at the reader's risk;

- will be liable for any losses and/or damages whether directly or indirectly from or arising in connection with the use of this article; and

- will be held responsible for any misuse, reuse, recycled and cited/uncited copies of content from by others.

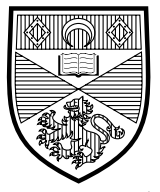

University of St Andrews
The St Andrews Network for Climate, Energy, Environment and Sustainability (STACEES) is an interdisciplinary research-focused initiative launched in April 2021 at The University of St Andrews.

The Sustainability Series comprises 15 professionally written, accessible articles commissioned by STACEES to showcase the breadth of the world-leading sustainability-focused research at the University.

Designed and produced by University of St Andrews Print \& Design Unit, September 2021. The University of St Andrews is a charity registered in Scotland. No: SC013532. 